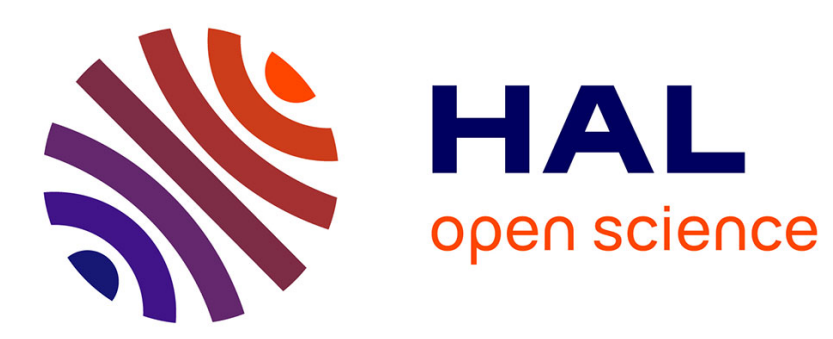

\title{
Synthesis of colloidal molecules: recent advances and perspectives
}

\author{
Rémi Merindol, Etienne Duguet, Serge Ravaine
}

\section{To cite this version:}

Rémi Merindol, Etienne Duguet, Serge Ravaine. Synthesis of colloidal molecules: recent advances and perspectives. Chemistry - An Asian Journal, 2019, 14 (19), pp.3232-3239. 10.1002/asia.201900962 . hal-02294405

\section{HAL Id: hal-02294405 \\ https://hal.science/hal-02294405}

Submitted on 21 Jul 2020

HAL is a multi-disciplinary open access archive for the deposit and dissemination of scientific research documents, whether they are published or not. The documents may come from teaching and research institutions in France or abroad, or from public or private research centers.
L'archive ouverte pluridisciplinaire HAL, est destinée au dépôt et à la diffusion de documents scientifiques de niveau recherche, publiés ou non, émanant des établissements d'enseignement et de recherche français ou étrangers, des laboratoires publics ou privés. 
Synthesis of colloidal molecules: recent advances and perspectives

Rémi Mérindol, ${ }^{[\mathrm{a}]}$ Etienne Duguet ${ }^{[\mathrm{b}]}$ and Serge Ravaine ${ }^{\star[a]}$

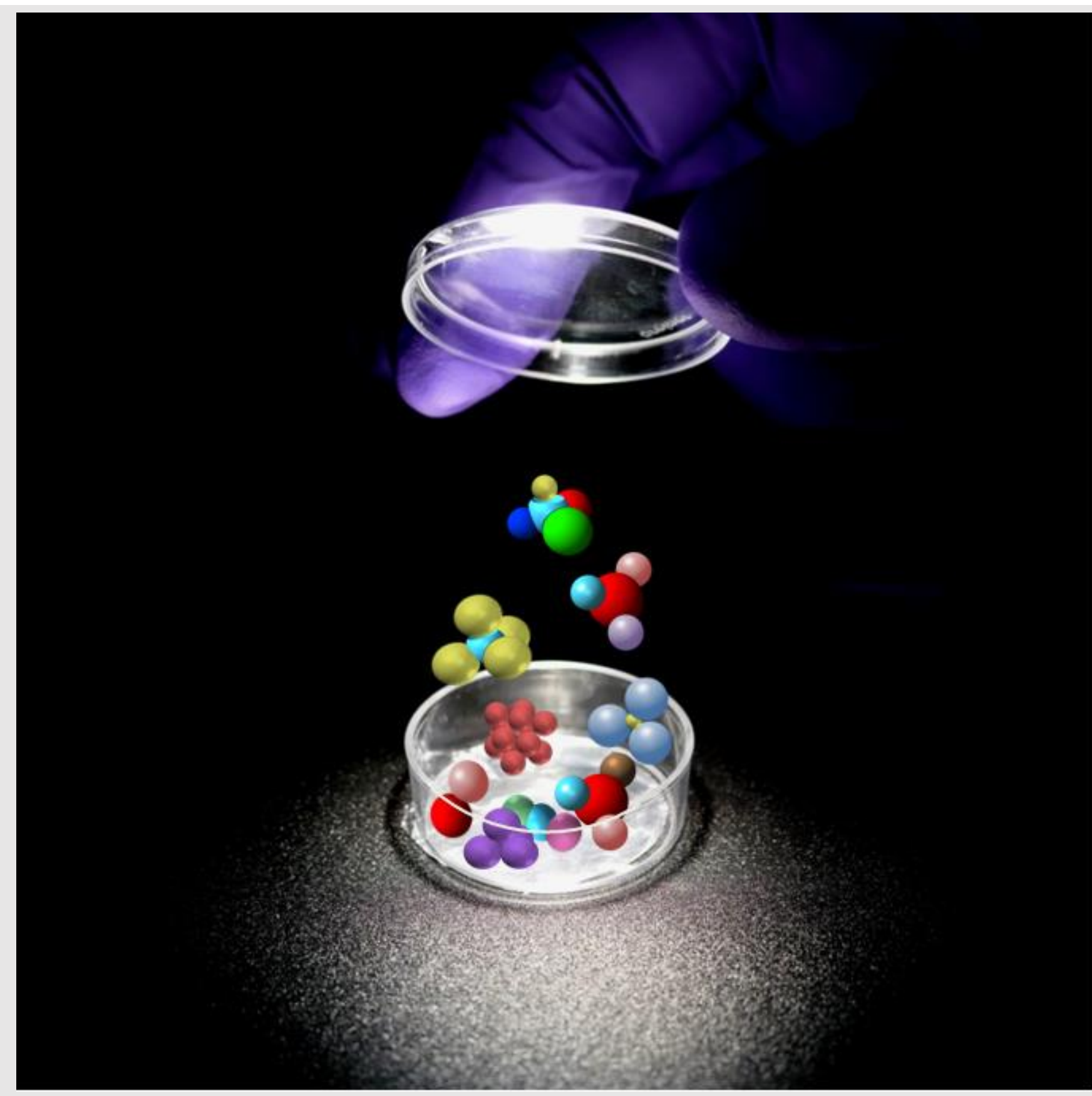


Abstract: The synthesis and study of colloidal molecules, that is to say clusters of a small number of colloidal entities that resemble the configuration of atoms in molecules both in constituent size and angular arrangement to that of valence shell electron pair repulsion model-related space-filling geometries, are of continued and significant interest. The rapid development in this research area has attracted intense interest from researchers with diverse expertise, and numerous methods towards the synthesis of colloidal molecules have been reported. In this Focus Review, we attempt to give an overview of these latest developments classifying them in processes based on controlled phase separation phenomena, on controlled surface nucleation and growth, and on controlled clustering. We also discuss the potential use of colloidal molecules as building blocks to fabricate new hierarchically organized superstructures and functional materials.

\section{Introduction}

The development of synthesis strategies capable of generating large amounts of size- and shape-monodisperse batch of particles and nanoparticles has considerably enriched both our capability to fabricate new functional materials and our current understanding on various physical phenomena. Spherical colloids have indeed enabled experiments to test and verify many theoretical models, e.g. the Mie theory that describes the optical scattering features of an individual particle, and the DerjaguinLandau-Verbey-Overbeek (DLVO) model dealing with the interaction forces between particles. To some extent, colloidal spheres are considered as the mesoscopic counterparts of atoms (and ions), and they are more and more often called "colloidal atoms" (CAs). The concept of "colloidal molecules" (CMs) was introduced in 2003 by van Blaaderen ${ }^{[1]}$ considering the symmetrical clusters of a few spherical particles reported by Pine and coworkers $^{[2]}$ and predicting that molecules form more complex materials than atoms do. ${ }^{[3]}$

In a more restrictive manner, we defined CMs as clusters of spheres with shapes resembling space-filling models of simple molecules. ${ }^{[4]}$ We also proposed a classification using and extending the well-known formalism of Gillespie derived from the Valence Shell Electron Pair Repulsion model (Figure 1). These CMs are expected to show complex behaviour (like low molecular weight compounds) not only dictated by the shape of the clusters, but also by the variety of the interactions they could generate, especially when the chemical composition or the surface chemistry of the constitutive CAs are different, e.g. $A X_{n} E_{m}$ or $A X Y$ like morphologies.
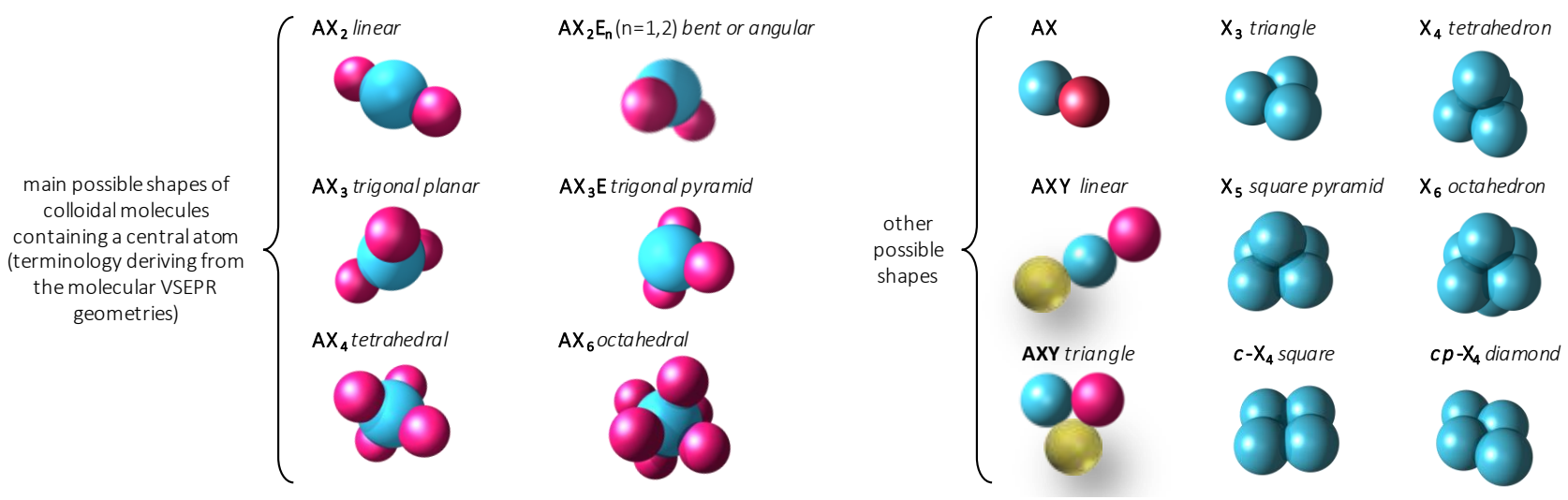

Figure 1. Extract of the classification proposed earlier ${ }^{[4]}$ for $\mathrm{CMs}$ based on spheres mimicking space-filling models of simple molecules.

[a] Dr Rémi Mérindol and Prof Serge Ravaine

Centre de Recherche Paul Pascal (CRPP, UMR 5031)

CNRS, Univ. Bordeaux

115 avenue du Dr Albert Schweitzer, 33600 Pessac, France

E-mail: serge.ravaine@crpp.cnrs.fr

[b] Prof Etienne Duguet

Institut de Chimie de la Matière Condensée de Bordeaux (ICMCB,

UMR 5026)

CNRS, Univ. Bordeaux, Bordeaux INP

87 avenue du Dr Albert Schweitzer, 33600 Pessac, France

The ORCID identification number(s) for the author(s) of this article can be found under:
In 2011, we reviewed this field by compiling and comparing the synthesis routes reported until then to get robust aggregates of spherical particles or nanoparticles with a special emphasis on the morphology control. ${ }^{[4]}$ We showed that these routes derived from two main strategies. The first one concerns $A X_{n} E_{m}$-type $C M s$ and starts from a single $C A$, which is then decorated by satellite colloids by taking advantage of controlled nucleation/growth or phase separation phenomena. The second one consists in the controlled clustering of preformed particles directed by coalescence, physical routes, chemical routes, or 2-D/3-D geometrical confinement. We propose here an update by reviewing the most significant works published these last eight years. The reader has to refer to our previous review ${ }^{[4]}$ to embrace http 
the full story and/or to read other excellent recent reviews written by others and addressing the field from other angles. ${ }^{[5-13]}$

Rémi Mérindol received an engineering diploma from the Graduate School of Chemistry of Montpellier, with a specialization in Material Chemistry, and a PhD in Physical Chemistry, in 2014, from the University of Strasbourg. He is currently postdoctoral fellow at the Centre de Recherche Paul Pascal (Bordeaux) where he develops the DNA driven assembly of colloidal molecules. His research interests include molecular control in hierarchical self-

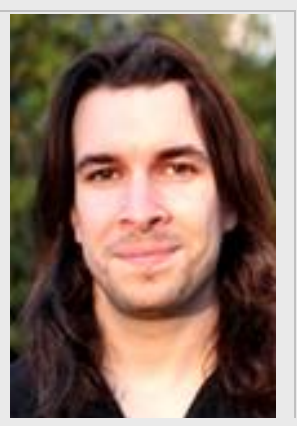
assembly and structure property relationships in soft-materials.

Etienne Duguet received his $\mathrm{PhD}$ in Polymer chemistry from the University of Bordeaux. He's now full Professor in the Chemistry Department, team leader at the Institute of Condensed Matter Chemistry of Bordeaux and managing director of the AMADEus laboratory of excellence. His research activities concern the design of complex composition and morphology nanoparticles such as patchy colloids, and the study of their assembly especially for applications as metamaterials in the optical range.

Serge Ravaine received his Ph.D. degree in physical-chemistry from the University of Bordeaux under the guidance of Dr. Pierre Delhaès and Prof. Didier Astruc. He then joined the group of Prof. Daniel R. Talham at the University of Florida in Gainesville. He went back to the University of Bordeaux to start his independent career first as an associate professor and as a full Professor since 2004. His research interests concern the synthesis of colloidal molecules and

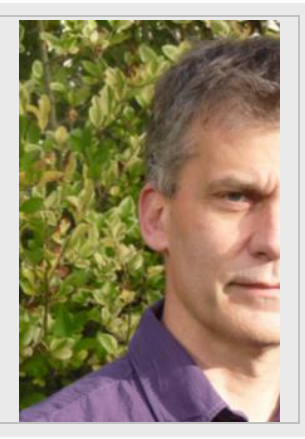

patchy particles and the fabrication of plasmonic/photonic materials by bottom-up approaches.

\section{Processes based on controlled phase separation phenomena}

The main achievements concerned synthesis techniques deriving from phase separation of immiscible macromolecules and leading to anisotropic polymer particles. ${ }^{[10,14]}$

The historical way was cleared in the 80s' when emulsion polymerization of organic monomers was experienced in the presence of cross-linked polymer seeds. The anisotropy arises from the immiscibility of the second stage polymer in cross-linked polymer networks, leading to the formation of a protrusion on one side of the seed particle. ${ }^{[4]}$ The phenomenon can be emphasized by increasing either the monomer/seed swelling ratio, the seed size, the seed cross-linking density, the temperature, etc. This process readily obtained homogeneous batches of polymer/polymer AX-type CMs. That is why obtaining a second surface protrusion was achieved by a second seed-growth emulsion polymerization leading to linear ( $\mathrm{AX}_{2}$-type), triangular ( $\mathrm{X}_{3}$-type), diamond-like (c- $\mathrm{X}_{4}$-type) and water-like $\left(\mathrm{AX}_{2} \mathrm{E}_{2}\right.$-type $)$ CMs by playing with the cross-linking density of the two first nodules. ${ }^{[15-17]}$ The simultaneous development of several protrusions can be achieved when the seed polymer is more polar than the second stage polymer and when the glass transition temperature of the latter is less than the polymerization temperature, but without control of the protrusion number, size and positions on the central latex seed. ${ }^{[18]}$ Improvements were published more recently with $\mathrm{AX}_{3} \mathrm{E}$ - and $\mathrm{AX}_{2} \mathrm{E}_{2}$-type $\mathrm{CMs}$ made of PS for the central nodule and poly(4-vinylpyridine) (P4VP) for the satellite ones. ${ }^{[19]}$ Moreover, $\mathrm{AX}_{2}$-type $\mathrm{CMs}$ were obtained in one stage from 3- $\mu \mathrm{m}$ latex seed made of cross-linked PMMA. ${ }^{[20]}$ Realtime optical microscopy showed that in the first moments a large number of small droplets of swelling monomer form simultaneously on the surface of the seeds, and then fuse until two protrusions remaining on the opposite sides. A subsequent polymerization made the structures permanent. Alternatively, AXtype morphology can spontaneously be achieved by solvent evaporation from PS/PMMA/toluene droplets dispersed in an aqueous solution of a non-ionic surfactant. ${ }^{[1]}$ The phase separation phenomenon was well predicted by the spreading coefficients analysis, even if the as-obtained CMs remained sizepolydisperse because of the polydispersity of the precursor emulsion. ${ }^{[22]}$ Recent efforts showed that this solvent-evaporative emulsion technique applied to block copolymers allows to get much regular and diverse CMs. ${ }^{[14]}$ In this way, PS-block-P4VP was initially dissolved in chloroform, and the solution was subsequently emulsified in a bad solvent for PS, e.g. water. Evaporating the chloroform led to AX-type CMs made of a PS nanoparticle with one P4VP protrusion and whose aspect ratio is controlled by the P4VP fraction. ${ }^{[23]}$ This method is robust without the requisites of narrow molecular weight distribution and a specific range of block fraction of the copolymers. Later, the strategy was extended for the synthesis of PS nanoparticles with up to nine P4VP protrusions ( $\mathrm{AX}_{9}$-type $\mathrm{CMs}$ ) by increasing the volume of the emulsion droplet, i.e. the volume of the particle (Figure 2a). ${ }^{[24,25]}$ For a given particle volume, the morphology can also be precisely tuned by modulating the interfacial interaction at the particle/water interface using a mixture of two different surfactants. ${ }^{[25]}$

\section{Processes based on controlled surface nucleation and growth}

This synthesis pathway, which leads essentially to $A X_{n}$-type CMs, consists in the nucleation and growth of the satellite colloids on a preformed inorganic seed. ${ }^{[4]}$ 
A first series of examples concern nanosized crystals, e.g. metals, metal oxides, sulfides or selenides, which undergo the heteroepitaxial growth of inorganic crystals and the formation of solid-state bonding interfaces. Biphasic crystals (AX-type CMs) are predominantly obtained, but the number of satellites can reach the value of 4 even 6 . Generally, the larger the seed and/or the lower the solvent polarity, the higher the satellite number. ${ }^{[6]}$ But in other systems, the control parameters are the temperature and/or relative precursor to seed proportions. Nevertheless, the satellite crystals are generally regular nor in size and shape, neither in their positions on the seed surface.

The second series of examples deals with inorganic seeds and polymer satellites that can be generated through seed-growth free-radical emulsion polymerization of organic monomers, e.g. styrene. We developed indeed an efficient protocol using silica seeds of few tens of nanometers previously treated in low surface density by compatibilizers, e.g. methacryloxyalkyltrimethoxysilane, in order to create reactive loci for promoting the surface capture of the growing macromolecules and therefore the nucleation of the polystyrene (PS) latex satellites. ${ }^{[26,27]}$ We obtained highly-symmetrical $\mathrm{AX}_{4}$ - and $\mathrm{AX}_{6}$-type CMs with morphology yield as high as $80 \%$ and the concept was extended to $A X_{3^{-}}, A X_{2^{-}}$and $A X$-type $C M$ s. The very regular shape of these CMs is mainly controlled by the steric repulsion and position optimization of the PS latex nodules

during the growth stage. ${ }^{[28]}$

Whatever the method used for growing the satellite colloids, these are identical especially from the viewpoint of their chemical composition because they are simultaneously generated. In order to diversify the chemical nature of the satellites and therefore to get more complex CMs, e.g. $\mathrm{AX}_{n} \mathrm{Y}_{\mathrm{m}}$-type CMs, a few authors reported recently the implementation of a second seed-growth stage. The main issue to overcome is to promote this second nucleation/growth mechanism on the initial central seed and not on the satellite particles obtained from the first stage.

In this way, biphasic crystalline AX-type CMs obtained by heteroepitaxial growth were subjected to the precursors of a third component to achieve triphasic AXY-type CMs. For instance, in the presence of $\mathrm{Fe}_{3} \mathrm{O}_{4}-\mathrm{Pt}$, the third component, e.g. $\mathrm{Au}, \mathrm{Ag}, \mathrm{Ni}$, $\mathrm{Pd}, \mathrm{PbS}$ or $\mathrm{Cu}_{\mathrm{x}} \mathrm{S}_{\mathrm{y}}$, exclusively grows on the $\mathrm{Pt}$ domain without formation of the other isomer side-products (Figure 2b). ${ }^{[29]}$ This chemoselectivity was initially assumed to correlate with the electron enrichment of the Pt crystals due to charge transfer from the adjacent $\mathrm{Fe}_{3} \mathrm{O}_{4}$ crystal. But electron microscopy investigations on the $\mathrm{Fe}_{3} \mathrm{O}_{4}-\mathrm{Pt}-\mathrm{Ag}$ system showed that in the first moments $\mathrm{Ag}$ nucleate on both domains, and then surface diffuse and coalesce onto the Pt one. ${ }^{[30]}$ In order to promote the formation of the other isomer, namely $\mathrm{Ag}-\mathrm{Fe}_{3} \mathrm{O}_{4}-\mathrm{Pt}$, the organic-chemistry concept of protecting group was extended by creating a thin amorphous shell of iron oxide on the $\mathrm{Pt}$ domain of the $\mathrm{Fe}_{3} \mathrm{O}_{4}-\mathrm{Pt}$ seed to redirect successfully the $\mathrm{Ag}$ nucleation to the otherwise disfavored $\mathrm{Fe}_{3} \mathrm{O}_{4}$ site. ${ }^{[31]}$ It may be observed that the as-obtained AXY-type CMs are not systematically linear.
We developed a similar strategy in creating an extra poly(methyl methacrylate) (PMMA) nodule on the silica/PS AX-type CMs obtained by seed-growth emulsion polymerization. ${ }^{[32]}$ To promote the growth of the PMMA latex on the silica core and avoid that MMA swell the PS nodule and polymerize within it, we previously treated the silica surface with a cationic initiator, namely 2,2'azobis(N,N'-dimethylene isobutyramidine) dihydrochloride. We observed the formation of linear AXY-type CMs where the PMMA latex stands on the initially free silica hemisphere in mainly linear arrangements (Figure 2c). As far as we know, there is no reported work dealing with such strategies applied to a final number of satellites higher than two.

\section{Processes based on controlled clustering}

\subsection{Clustering of isotropic colloids}

\subsubsection{Assisted by external fields}

The application of an external alternating-current electric field has been reported to be an efficient and simple way to create CMs based on spherical particles, which experience anisotropic dipolar and dielectrophoretic interactions. ${ }^{[33]}$ Magnetic field microgradients established in a paramagnetic fluid have been used as virtual moulds to act as templates for the production of a variety of $C M s$, including $A_{4^{-}}, A_{5^{-}}, A_{6^{-}}, A X_{2^{-}}, A X_{3^{-}}$and $A X_{4}$-types (Figure 2d). ${ }^{[34]}$ The assembly of spherical particles into CMs has also been driven by a magneto-acoustic method, in which the magnetic field is used to control the interparticle interactions and the acoustic field controls the local density of particles by attracting them to the pressure nodes of the standing wave. ${ }^{[35]}$

\subsubsection{Assisted by geometrical confinement}

The use of templates to fabricate CMs from spherical particles has been extensively reported. ${ }^{[4]}$ For example, the patterning of 2-D substrates with hydrophilic patches ${ }^{[36]}$ or traps ${ }^{[37]}$ allowed the controlled deposition of micron-sized particles, resulting in the creation of a wide library of CMs (Figure 2e), including 3-D chiral objects. The strategy which consists in the adsorption of particles onto emulsion droplets used as 3-D templates (Pickering effect) followed by their coagulation through the droplet phase evaporation is particularly straightforward. ${ }^{[38]}$ This route recently led to the formation of CMs with externally tunable interaction sites. ${ }^{[39]}$ Another method of interest for the preparation of CMs relies on the use of binary colloidal crystals as templates. It allowed the preparation of CMs made of soft microgels via photo initiated thiol-ene click reaction ${ }^{[40,41]}$ and of $\mathrm{CMs}$ of spheres covered with complementary DNA strands by taking benefit of the cooperative formation of hydrogen bonds between them, called hybridization. ${ }^{[42,43]}$ By variation of the size ratio of the two types of DNAylated spheres, different CMs symmetries could be obtained (Figure 2f). 
a
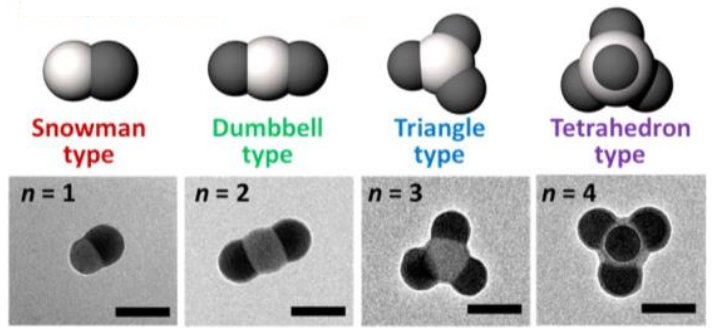

d

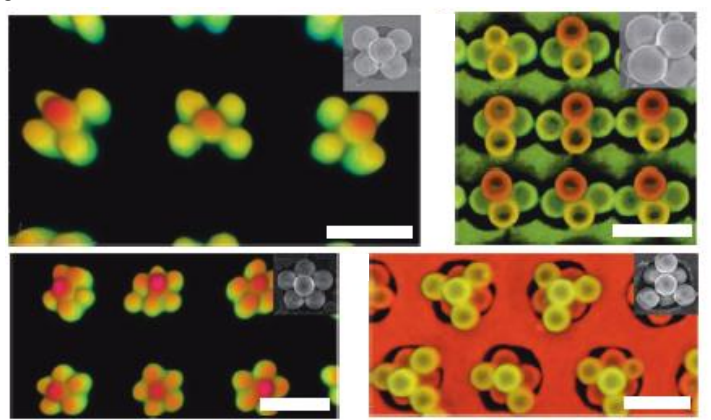

b
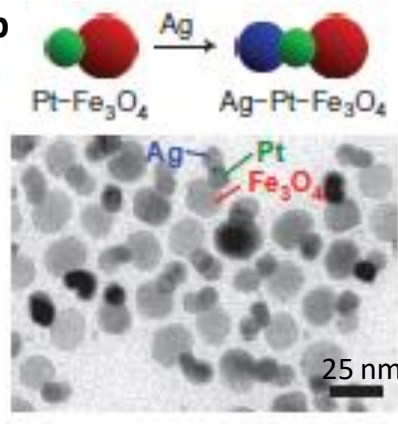

e

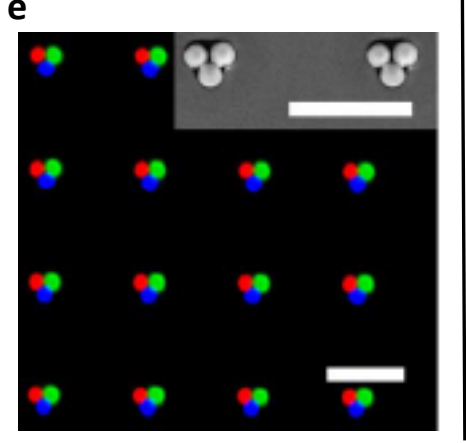

c

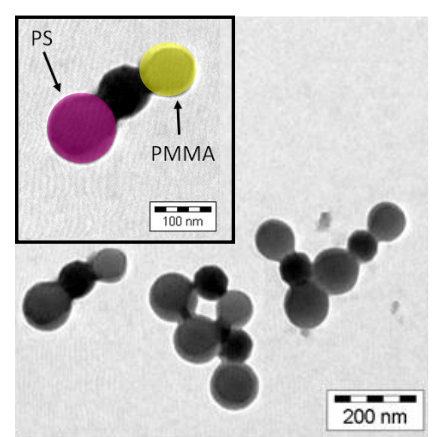

f

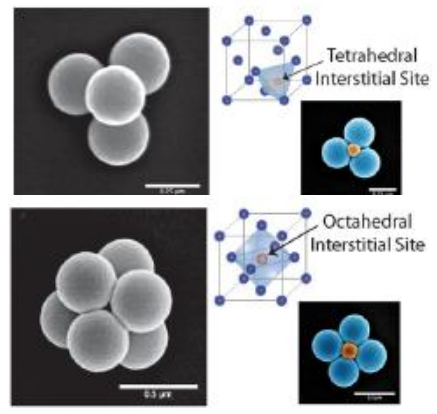

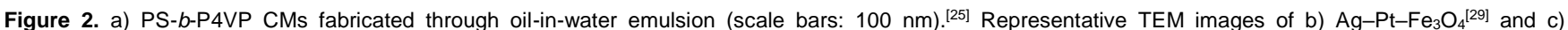
PMMA/silica/PS ${ }^{[32]}$ heterotrimers mimicking AXY-type CMs. d) CMs of diamagnetic particles with $X_{5}, X_{4}, X_{6}$ and $X_{7}$ geometries (scale bars: $2 \mu$ m). ${ }^{[34]}$ e) $A X Y$-like CMs assembled by sequential capillarity-assisted assembly (scale bars: $5 \mu \mathrm{m}$ ). ${ }^{[37]} \mathrm{f}$ ) SEM images of tetrahedral and octahedral CMs produced using a colloidal crystal as a template (scale bars: $250 \mathrm{~nm}$ (top) and $500 \mathrm{~nm}$ (bottom). ${ }^{[43]}$

\subsubsection{Assisted by physical or chemical interactions}

Even if the clustering of spherical particles by depletion forces ${ }^{[44]}$ or hydrodynamic dipolar interactions ${ }^{[45]}$ have been reported, a large number of recent studies dedicated to CMs formation are based on DNA hybridization. Using this strategy it was possible to form $\mathrm{CMs}$ with $\mathrm{AX}_{2^{-}}, \mathrm{AX}_{3^{-}}, \mathrm{AX}_{4^{-}}$and $\mathrm{AX}_{6^{-}}$-morphologies with high yield, simply by choosing the appropriate size ratio between the spherical building units. ${ }^{[46]}$ Another series of experiments concern the use of colloids functionalized with surface mobile DNA linkers as building blocks. ${ }^{[47,48]}$ It was possible to create flexible CMs which are physically stable but reorganise in permanence at high speed (Figure 3a). ${ }^{[49]}$ The sequence programmable folding of a plasmid by DNA staple strands, also called DNA origami, which allows one to design nanoscale DNA architectures with extensive shape control, has also been used to template the organization of DNA coated particles. One can place a gold nanoparticle in the center of an origami to create square-shaped or cross-shaped CMs. ${ }^{[50]}$ By locating DNA-functionalized gold nanoparticles at the vertices of a DNA origami octahedron, $C M s$ with $O_{h}$ symmetry have been obtained. Furthermore, the introduction of three different DNA at chosen vertices of the origami frame combined with the use of three pairs of gold nanoparticles with different sizes and respectively complementary DNA shells allowed the realization of chiral $\mathrm{CMs}^{\left[{ }^{[51]}\right.} \mathrm{CMs}$ that resemble the methane molecule were obtained by the encapsulation of a DNA-coated gold nanoparticle into a tetrahedral DNA cage, which induced that it can only interact with other DNA-coated gold NPs through the four faces of the tetrahedron because of both electrostatic repulsion and steric hindrance. ${ }^{[52]} \mathrm{SF}_{6}$-like octahedral $\mathrm{CMs}$, $\mathrm{W}\left(\mathrm{CH}_{3}\right)_{6}$-like triangular prismatic $\mathrm{CMs}$ and even ethane-like $\mathrm{CMs}$ were also produced by this promising approach (Figure $3 b$ ).

Here the main improvement compared to previous approaches is that using origami with bundled duplex, instead of structures formed from a single DNA duplex, greatly improves the rigidity of the synthesized CMs.

\subsection{Clustering of patchy particles}

In order to create CMs by bottom-up assembly routes, it is of primary importance to control both the strength and the directionality of the interactions between the building blocks. Colloidal particles with site-specific directional interactions, socalled "patchy particles", are promising candidates to fulfil this requirement, if one can control the location, size and geometry of the patches. ${ }^{[53]}$

\subsubsection{Janus particles}

Janus particles, named after the ancient roman god Janus, ${ }^{[54]}$ are a subclass of patchy particles and have been extensively used as building units for CMs in the last few years. Dumbbell-like Janus particles were reported to assemble into CMs thanks to a difference of the softness, ${ }^{[55]}$ surface roughness, ${ }^{[56]}$ chemical 
nature ${ }^{[57]}$ or size ${ }^{[58]}$ of their two constitutive lobes. CMs with different morphologies have also been produced through assembly Janus particles driven by magnetostatic binding forces, ${ }^{[59]}$ capillary bridging, ${ }^{[60,61]}$ host-guest interaction ${ }^{[62]}$ and DNA hybridization. ${ }^{[63,64]}$

\subsubsection{Particles with more than one patch}

When particles can interact with more than one binding site on their surface, i.e. patches, it enables the formation of more complex CMs. It was thus reported that particles with a specific number of so-called entropic patches (i.e. cavities) that display well-defined symmetries can assemble with multiple complementary spherical particles via depletion interaction ${ }^{[65]}$ or spherical droplets via preferential wetting, ${ }^{[66]}$ forming CMs with well-defined geometries. We developed a similar strategy in promoting the covalent attachment of complementary nanospheres with silica nanoparticles with 2,3 or 4 dimples through the selective functionalization of PS residues remaining at the bottom of the dimples. ${ }^{[67,68]}$ By varying the relative amounts of both precursors, the size or the chemical composition of the complementary nanospheres, we created a large variety of CMs, including chiral ones (Figure $3 \mathrm{c}$ ). An alternative approach is based on the use of particles with enthalpic patches, i.e. zones at their surface which exhibit specific interactions, as precursors. Spherical particles with a precise numbers of liquid patches were shown to connect with neighbouring spherical particles via liquid bonds. ${ }^{[69]}$ These ones can be permanently fixed by polymerization, yielding to robust CMs (Figure $3 d$ ).

The specificity of DNA-hybridization has also been exploited to assemble CMs. First, $A X-, A X_{2^{-}}, A^{-} X_{3^{-}}$and $\mathrm{AX}_{4^{-}} \mathrm{CMs}$ were synthesized by mixing one-DNA patch particles with complementary one-, two-, three- and four-patch particles, respectively (Figure $3 \mathrm{e}$ ). ${ }^{[70]}$ Ethylene-like $\mathrm{CMs}$ were also obtained when two-patch particles with patches big enough to accommodate more two complementary monovalent particles were used. It was also reported that a DNA frame can be used to encode the surface of polymer particles. This technique allows to transfer specific sequences and positional information from the DNA frame directly onto the particle surface, and to later use this information to control the CMs geometry. ${ }^{[71]}$ In another study, DNA origamis were directly fixed around latex particles to make them patchy. Because each of the patches can be specifically addressed it is later possible to attach different colloids onto them to form chiral microscopic clusters with extensive control over the dihedral angle between the different constituents. ${ }^{[72]}$ Finally, an original strategy was developed recently, which consists in using mobile DNA origami rafts as sticky patches at the surface of oilin-water droplets. ${ }^{[33]}$ These patchy droplets assembled in CMs, whose geometry could be reversibly reconfigured via strand displacement (Figure 3f).
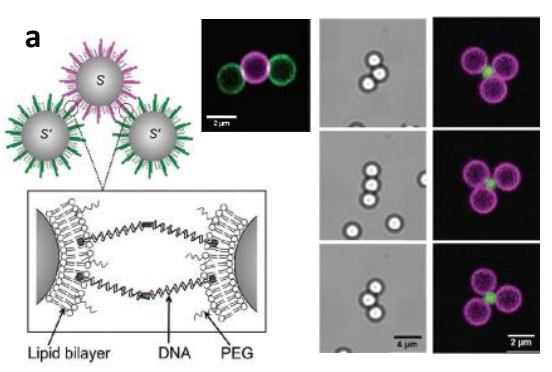

b

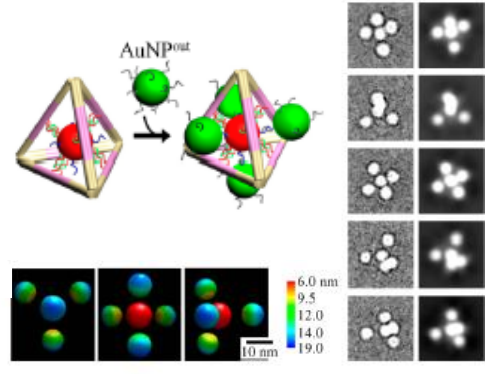

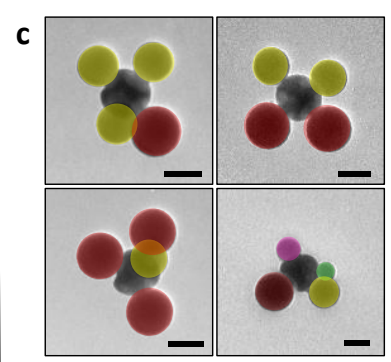

e
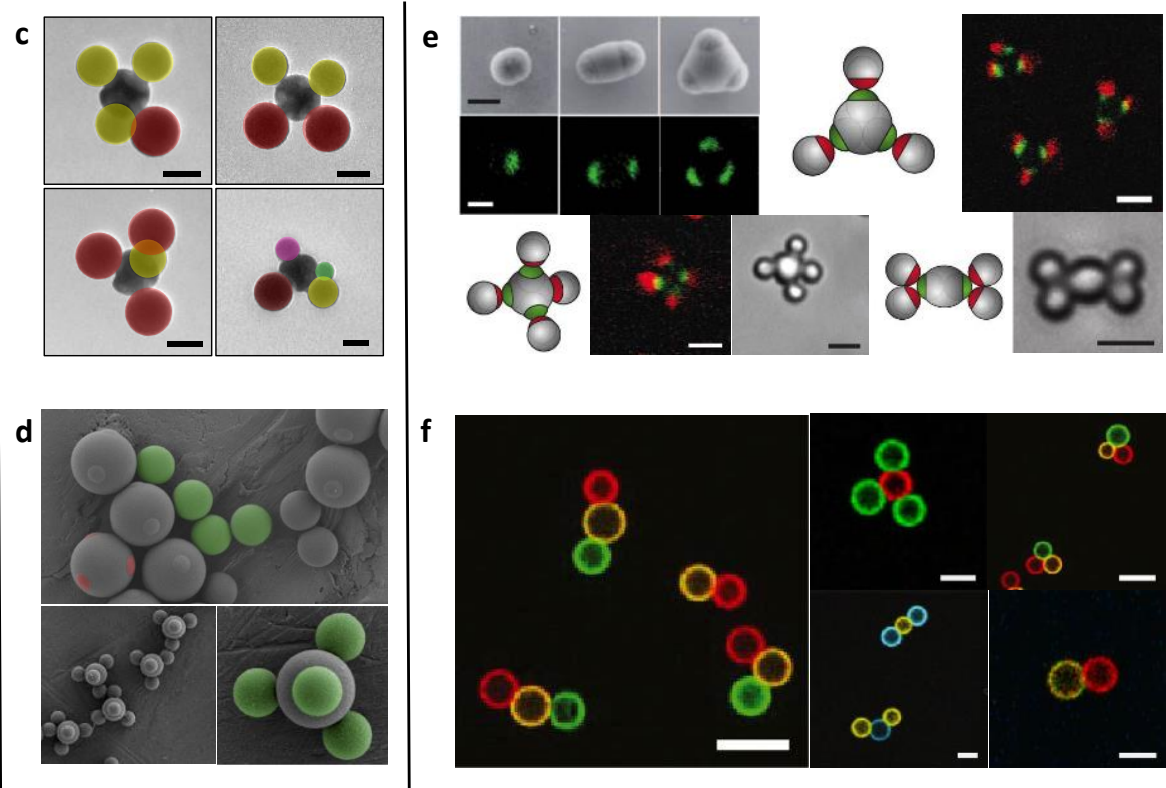

Figure 3. a) Schematic representation and confocal microscopy images of flexible CMs made from particles with mobile DNA linkers. ${ }^{[49]}$ b) Scheme, cryoEM images

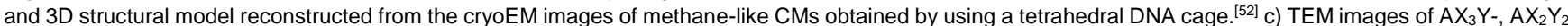

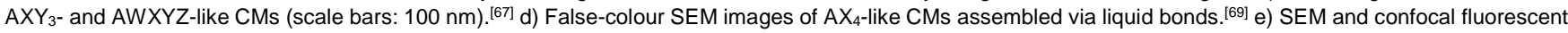
images of patchy particles used as CAs (scale bars: $500 \mathrm{~nm}$ ) and bright-field, confocal fluorescent and schematic images of CMs assembled from them (scale bars: $2 \mu \mathrm{m}){ }^{[70]}$ f) Confocal images of CMs produced from patchy oil-in-water droplets (scale bars: $5 \mu \mathrm{m}$ ). ${ }^{[73]}$ 


\section{Conclusions and outlook}

The review of the literature from the last years shows an increasing interest in the fabrication of CMs. Progress in the use of patchy particles, which can be considered as valence-endowed particles, as building blocks, has made possible the formation of a large panel of new CMs which were inaccessible with building blocks that interact through isotropic forces. Furthermore, the possibility to control not only the position but also the size and the chemical nature of each of the patches of the precursors opened the way to tune the geometry of the CMs.

Special mention should be made of methods based on DNA hybridization, which have been enormously developed in recent years. These methods have the advantages to take place in bulk, which allows scalable synthesis even if the relatively high price of DNA still hinders their development.

The recent efforts to produce CMs have also been fuelled by the aspiration to utilize them for building new hierarchically organized superstructures and ultimately, functional materials, by selfassembly. ${ }^{[8,74]}$ Recent works on mobile DNA links show that one can control the sequence of CMs assembly. ${ }^{[75]}$ This result, which reminds us the reactivity of organic molecules that can be temporarily protected, opens new routes for the production of colloidal superstructures. Moreover, it was shown that dumbbellshaped CMs were used as building units for the building of photonic crystals with a partial band gap, ${ }^{[76]}$ while the emergence of a complete 3D band gap has been predicted for such CMs embedded within a face-centered cubic template. ${ }^{[77]}$ It was also reported that $\mathrm{AX}_{6}$-type $\mathrm{CMs}$ can be self-assembled into ordered structures ${ }^{[66]}$ and that DNA-coated CMs with tetragonal geometry provide a way to build two new colloidal crystalline lattices: diamond and pyrochlore. ${ }^{[78]}$ One can thus reasonably assume that more complex superstructures could be self-assembled from other CMs (Figure 4), ${ }^{[79]}$ including chiral ones. This is an exciting challenge that deserves to be met in the near future. Another target is to expand the panel of reconfigurable CMs, whose geometry could be tuned on demand under external stimulus. Such building blocks would open new avenues for erasing the inherent defects occurring during the colloidal assembly process and for engineering new materials with properties that could be adjusted on demand.

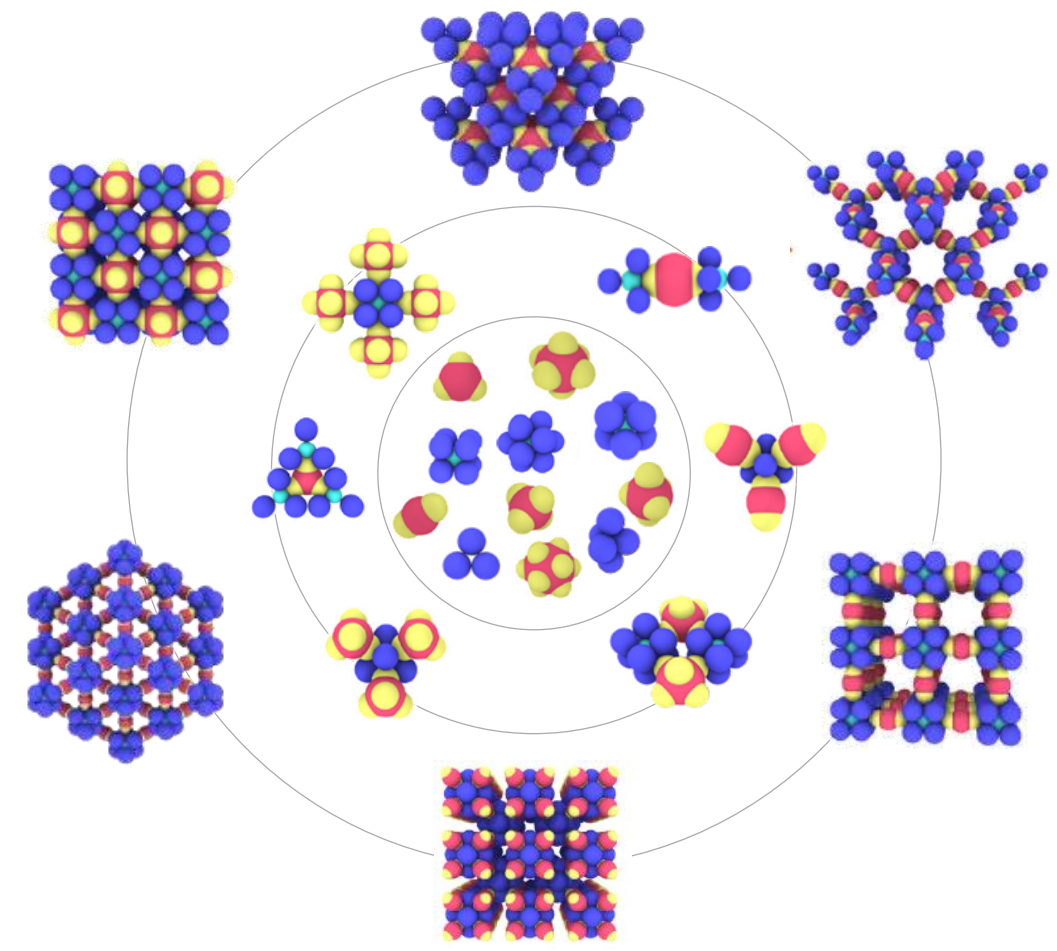

Figure 4. Possible superstructures and arrays composed of CMs that could be obtained by self-assembly. ${ }^{[79]}$

\section{Acknowledgements}

This work was supported by the Agence Nationale de la Recherche (ENLARgER project, ANR-15-CE09-0010), the LabEx AMADEUS (ANR-10-LABX-42) and IdEx Bordeaux (ANR-10IDEX-03-02), i.e. the Investissements d'Avenir programme of the
French government managed by the Agence Nationale de la Recherche. WL was supported by the China Scholarship Council.

\section{Conflict of interest}

The authors declare no conflict of interest. 
Keywords: colloidal molecules $•$ synthesis routes

[1] A. v. Blaaderen, Science 2003, 301, 470-471.

[2] V. N. Manoharan, M. T. Elsesser, D. J. Pine, Science 2003, 301, 483-487.

[3] A. van Blaaderen, Nature 2006, 439, 545-546

[4] E. Duguet, A. Désert, A. Perro, S. Ravaine, Chem. Soc. Rev. 2011, 40, 941-960.

[5] W. B. Rogers, W. M. Shih, V. N. Manoharan, Nat. Rev. Mater. 2016, 1, 16008 .

[6] R. Scarfiello, C. Nobile, P. D. Cozzoli, Front. Mater. 2016, 3, 1-29

[7] S. Ni, I. Buttinoni, H. Wolf, L. Isa, Chim. Int. J. Chem. 2017, 71, 349-353.

[8] D. Morphew, D. Chakrabarti, Curr. Opin. Colloid Interface Sci. 2017, 30, 70-80.

[9] E. Elacqua, X. Zheng, C. Shillingford, M. Liu, M. Weck, Acc. Chem. Res. 2017, 50, 2756-2766.

[10] B. Yu, H. Cong, Q. Peng, C. Gu, Q. Tang, X. Xu, C. Tian, F. Zhai, Adv. Colloid Interface Sci. 2018, 256, 126-151.

[11] S. Wintzheimer, T. Granath, M. Oppmann, T. Kister, T. Thai, T. Kraus, N. Vogel, K. Mandel, ACS Nano 2018, 12, 5093-5120.

[12] H. Löwen, Europhys. Lett. 2018, 121, 58001.

[13] A.-C. Genix, J. Oberdisse, Soft Matter 2018, 14, 5161-5179.

[14] K. H. Ku, J. M. Shin, H. Yun, G.-R. Yi, S. G. Jang, B. J. Kim, Adv. Funct. Mater. 2018, 28, 1802961.

[15] J.-W. Kim, R. J. Larsen, D. A. Weitz, Adv. Mater. 2007, 19, 20052009.

[16] J. Kim, R. J. Larsen, D. A. Weitz, J. Am. Chem. Soc. 2006, 128, 14374-14377.

[17] J.-G. Park, J. D. Forster, E. R. Dufresne, Langmuir 2009, 25, 89038906.

[18] J. M. Stubbs, D. C. Sundberg, Prog. Org. Coatings 2008, 61, 156165.

[19] M. Yang, G. Wang, H. Ma, Chem. Commun. 2011, 47, 911-913.

[20] B. Peng, A. van Blaaderen, A. Imhof, ACS Appl. Mater. Interfaces 2013, 5, 4277-4284.

[21] N. Saito, R. Nakatsuru, Y. Kagari, M. Okubo, Langmuir 2007, 23, 11506-11512.

[22] X. Ge, M. Wang, X. Ji, X. Ge, H. Liu, Colloid Polym. Sci. 2009, 287, 819-827.

[23] R. Deng, H. Li, J. Zhu, B. Li, F. Liang, F. Jia, X. Qu, Z. Yang, Macromolecules 2016, 49, 1362-1368.

[24] R. Deng, H. Li, F. Liang, J. Zhu, B. Li, X. Xie, Z. Yang, Macromolecules 2015, 48, 5855-5860.

[25] K. H. Ku, Y. Kim, G.-R. Yi, Y. S. Jung, B. J. Kim, ACS Nano 2015, 9, 11333-11341.

[26] A. Désert, I. Chaduc, S. Fouilloux, J.-C. Taveau, O. Lambert, M. Lansalot, E. Bourgeat-Lami, A. Thill, O. Spalla, S. Ravaine, et al., Polym. Chem. 2012, 3, 1130.

[27] A. Désert, J. Morele, J.-C. Taveau, O. Lambert, M. Lansalot, E. Bourgeat-Lami, A. Thill, O. Spalla, L. Belloni, S. Ravaine, et al., Nanoscale 2016, 8, 5454-5469.

[28] A. Thill, A. Désert, S. Fouilloux, J.-C. Taveau, O. Lambert, M. Lansalot, E. Bourgeat-Lami, O. Spalla, L. Belloni, S. Ravaine, et al.,
Langmuir 2012, 28, 11575-11583.

[29] M. R. Buck, J. F. Bondi, R. E. Schaak, Nat. Chem. 2012, 4, 37-44.

[30] J. M. Hodges, J. R. Morse, M. E. Williams, R. E. Schaak, J. Am. Chem. Soc. 2015, 137, 15493-15500

[31] J. M. Hodges, A. J. Biacchi, R. E. Schaak, ACS Nano 2014, 8, 1047-1055.

[32] I. Chaduc, J. Parvole, E. Duguet, S. Ravaine, M. Lansalot, E. Bourgeat-Lami, Polym. Chem. 2012, 3, 3232. F. Ma, D. T. Wu, N. Wu, J. Am. Chem. Soc. 2013, 135, 7839-7842. A. F. Demirörs, P. P. Pillai, B. Kowalczyk, B. A. Grzybowski, Nature 2013, 503, 99-103

[35] Y. Yang, A. T. Pham, D. Cruz, C. Reyes, B. J. Wiley, G. P. Lopez, B. B. Yellen, Adv. Mater. 2015, 27, 4725-4731.

[36] C. L. Wirth, M. De Volder, J. Vermant, Langmuir 2015, 31, 16321640.

[37] S. Ni, J. Leemann, I. Buttinoni, L. Isa, H. Wolf, Sci. Adv. 2016, 2, e1501779.

[38] C. S. Plüisch, A. Wittemann, in Adv. Colloid Sci. (Eds.: M.M. Rahman, A.M. Asiri), InTech, 2016, pp. 237-264.

[39] L. K. Månsson, J. N. Immink, A. M. Mihut, P. Schurtenberger, J. J. Crassous, Faraday Discuss. 2015, 181, 49-69.

[40] Q. Yuan, J. Gu, Y. Zhao, L. Yao, Y. Guan, Y. Zhang, ACS Macro Lett. 2016, 5, 565-568.

[41] L. Yao, Q. Li, Y. Guan, X. X. Zhu, Y. Zhang, ACS Macro Lett. 2018, 7, 80-84.

[42] J. T. McGinley, I. Jenkins, T. Sinno, J. C. Crocker, Soft Matter 2013 , 9, 9119.

[43] J. T. McGinley, Y. Wang, I. C. Jenkins, T. Sinno, J. C. Crocker, ACS Nano 2015, 9, 10817-10825.

[44] R. W. Perry, V. N. Manoharan, Soft Matter 2016, 12, 2868-2876.

[45] B. Shen, J. Ricouvier, F. Malloggi, P. Tabeling, Adv. Sci. 2015, 3, 17.

[46] N. B. Schade, M. C. Holmes-Cerfon, E. R. Chen, D. Aronzon, J. W. Collins, J. A. Fan, F. Capasso, V. N. Manoharan, Phys. Rev. Lett. 2013, 110, 148303.

[47] S. A. J. van der Meulen, M. E. Leunissen, J. Am. Chem. Soc. 2013 , 135, 15129-15134.

[48] L. Feng, L.-L. Pontani, R. Dreyfus, P. Chaikin, J. Brujic, Soft Matter 2013, 9, 9816.

[49] I. Chakraborty, V. Meester, C. van der Wel, D. J. Kraft, Nanoscale 2017, 9, 7814-7821.

[50] W. Liu, J. Halverson, Y. Tian, A. V. Tkachenko, O. Gang, Nat. Chem. 2016, 8, 867-873.

[51] Y. Tian, T. Wang, W. Liu, H. L. Xin, H. Li, Y. Ke, W. M. Shih, O. Gang, Nat. Nanotechnol. 2015, 10, 637-644

[52] Y. Li, Z. Liu, G. Yu, W. Jiang, C. Mao, J. Am. Chem. Soc. 2015 137, 4320-4323.

[53] S. Ravaine, E. Duguet, Curr. Opin. Colloid Interface Sci. 2017, 30, 45-53.

[54] A. Perro, S. Reculusa, S. Ravaine, E. Bourgeat-Lami, E. Duguet, J. Mater. Chem. 2005, 15, 3745.

[55] T. S. Skelhon, Y. Chen, S. A. F. Bon, Soft Matter 2014, 10, 77307735.

[56] D. J. Kraft, R. Ni, F. Smallenburg, M. Hermes, K. Yoon, D. A. Weitz, 
A. van Blaaderen, J. Groenewold, M. Dijkstra, W. K. Kegel, Proc. Natl. Acad. Sci. 2012, 109, 10787-10792.

X.-H. Ge, Y.-H. Geng, J. Chen, J.-H. Xu, ChemPhysChem 2018, 19, 2009-2013.

[58] F. Ma, S. Wang, D. T. Wu, N. Wu, Proc. Natl. Acad. Sci. 2015, 112, 6307-6312.

[59] S. Sacanna, L. Rossi, D. J. Pine, J. Am. Chem. Soc. 2012, 134 6112-6115.

[60] C. Yu, J. Zhang, S. Granick, Angew. Chemie Int. Ed. 2014, 53, 4364-4367.

[61] B. Bharti, D. Rutkowski, K. Han, A. U. Kumar, C. K. Hall, O. D. Velev, J. Am. Chem. Soc. 2016, 138, 14948-14953.

[62] S. Sagebiel, L. Stricker, S. Engel, B. J. Ravoo, Chem. Commun 2017, 53, 9296-9299.

[63] L. Feng, R. Dreyfus, R. Sha, N. C. Seeman, P. M. Chaikin, Adv. Mater. 2013, 25, 2779-2783.

[64] T. G. W. Edwardson, K. L. Lau, D. Bousmail, C. J. Serpell, H. F. Sleiman, Nat. Chem. 2016, 8, 162-170.

[65] Y. Wang, Y. Wang, X. Zheng, G. Yi, S. Sacanna, D. J. Pine, M. Weck, J. Am. Chem. Soc. 2014, 136, 6866-6869.

[66] Z. Luo, B. Liu, Angew. Chemie - Int. Ed. 2018, 57, 4940-4945.

[67] P.-E. Rouet, C. Chomette, E. Duguet, S. Ravaine, Angew. Chemie Int. Ed. 2018, 57, 15754-15757.

[68] P.-E. Rouet, C. Chomette, L. Adumeau, E. Duguet, S. Ravaine, Beilstein J. Nanotechnol. 2018, 9, 2989-2998.
Z. Gong, T. Hueckel, G.-R. Yi, S. Sacanna, Nature 2017, 550, 234 238.

[70]

Y. Wang, Y. Wang, D. R. Breed, V. N. Manoharan, L. Feng, A. D. Hollingsworth, M. Weck, D. J. Pine, Nature 2012, 491, 51-55.

[71] T. Trinh, C. Liao, V. Toader, M. Barłóg, H. S. Bazzi, J. Li, H. F. Sleiman, Nat. Chem. 2018, 10, 184-192.

[72] M. Y. Ben Zion, X. He, C. C. Maass, R. Sha, N. C. Seeman, P. M. Chaikin, Science (80-. ). 2017, 358, 633-636.

[73] Y. Zhang, X. He, R. Zhuo, R. Sha, J. Brujic, N. C. Seeman, P. M. Chaikin, Proc. Natl. Acad. Sci. 2018, 115, 9086-9091.

[74] D. Morphew, J. Shaw, C. Avins, D. Chakrabarti, ACS Nano 2018, 12, 2355-2364.

[75] Y. Zhang, A. McMullen, L.-L. Pontani, X. He, R. Sha, N. C. Seeman, J. Brujic, P. M. Chaikin, Nat. Commun. 2017, 8, 21.

[76] J. D. Forster, J.-G. Park, M. Mittal, H. Noh, C. F. Schreck, C. S. O'Hern, H. Cao, E. M. Furst, E. R. Dufresne, ACS Nano 2011, 5, 6695-6700.

[77] K. I. Morozov, A. M. Leshansky, Langmuir 2019, 35, 3987-3991.

[78] E. Ducrot, M. He, G.-R. Yi, D. J. Pine, Nat. Mater. 2017, 16, 652657.

[79] K. Aryana, J. B. Stahley, N. Parvez, K. Kim, M. B. Zanjani, Adv. Theory Simulations 2019, 2, 1800198 


\section{MINIREVIEW}

This review highlights achievements made in the synthesis of colloidal molecules that have emerged in recent years, including methods based on DNA hybridization. Some potential applications of colloidal molecules are also described.

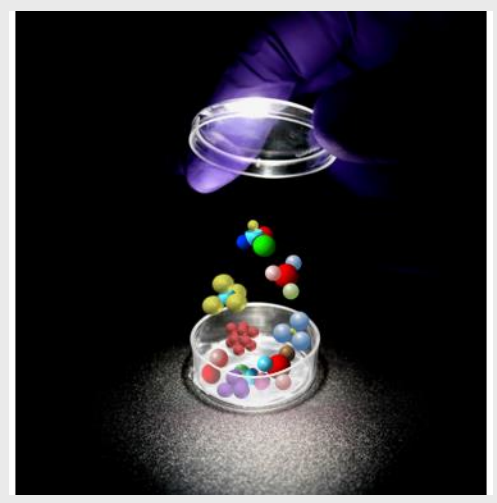

Rémi Mérindol, Etienne Duguet and Serge Ravaine*

Page No. - Page No.

Synthesis of colloidal molecules: recent advances and perspectives 